\title{
Relationship of pharmacist interaction with patient knowledge of dispensed drugs and patient satisfaction
}

A. Garjani, ${ }^{1}$ M. Rahbar, ${ }^{1}$ T. Ghafourian, ${ }^{2}$ N. Maleki, ${ }^{1}$ Af. Garjani, ${ }^{3}$ M. Salimnejad, ${ }^{4}$ M. Shamsmohammadi, ${ }^{4}$ V. Baghchevan ${ }^{4}$ and H. Aghajani ${ }^{4}$

$$
\begin{aligned}
& \text { العلاقة بين تفاعل الصيدلي مع معارف المرضى عن الأدوية الموصوفة لمم وإرضائهم }
\end{aligned}
$$

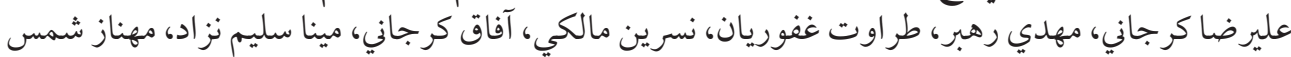

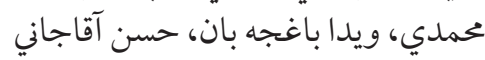

$$
\begin{aligned}
& \text { الخلاصسة: أجرى الباحثون دراسة استباقية تناولت مهام الصيادلة ومعارف المرضى وإرضاءهم في } 35 \text { من }
\end{aligned}
$$

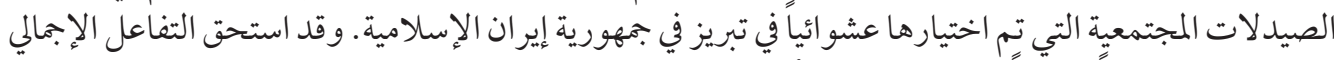

$$
\begin{aligned}
& \text { لدى الصيادلة حرزاً وسطياً مقداره } 3.05 \text { من أصل 5. }
\end{aligned}
$$

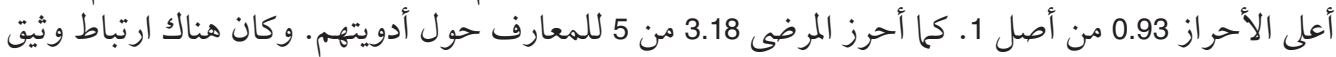

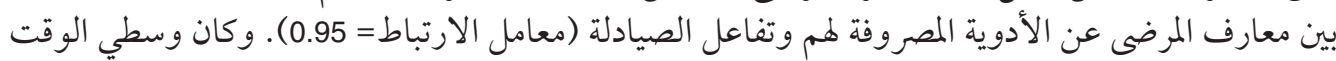

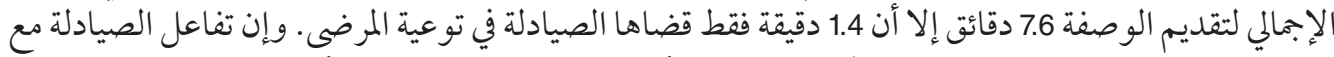

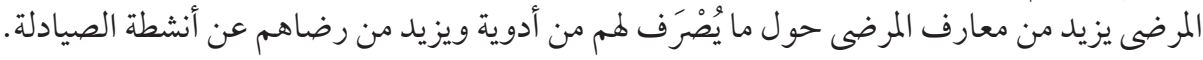

ABSTRACT A prospective survey of pharmacists' tasks and patients' knowledge and satisfaction was conducted in 35 randomly selected community pharmacies in Tabriz, Islamic Republic of Iran. The total pharmacist interaction received a mean score of 3.05 out of 5 . Providing written directions for use attained the highest score of 0.98 out of 1 . Patients scored 3.18 out of 5 for knowledge about their medicines. There was a close correlation between patients' knowledge of dispensed drugs and pharmacist interaction $(r=0.95)$. Mean total prescription filling time was $7.6 \mathrm{~min}$, but only $1.4 \mathrm{~min}$ was spent on pharmacist-patient counselling. The interaction between pharmacist and patient increases patients' knowledge about dispensed medicines and their satisfaction with the pharmacist's activities.

Rapport entre le dialogue pharmacien-patient, les connaissances du patient relatives aux médicaments délivrés et la satisfaction de ce patient

RÉSUMÉ Une étude prospective sur le rôle des pharmaciens et sur les connaissances et la satisfaction des patients a été réalisée dans 35 pharmacies de secteur sélectionnées au hasard à Tabriz (République islamique d'Iran). Le dialogue avec le pharmacien a obtenu un score moyen de 3,05 sur 5. L'écriture par le pharmacien de la posologie a donné lieu au score le plus élevé, à savoir 0,98 sur 1. Le score de 3,18 sur 5 a été atteint sur le point des connaissances des patients concernant leurs médicaments. II existait une étroite corrélation entre les connaissances des patients sur les médicaments délivrés et le dialogue avec le pharmacien $(r=0,95)$. La durée totale moyenne de l'exécution de l'ordonnance était de 7,6 minutes, mais le pharmacien ne consacrait que 1,4 minute à dispenser des conseils aux patients. Le dialogue entre le pharmacien et le patient permet à celui-ci d'avoir une meilleure connaissance des médicaments délivrés et augmente sa satisfaction vis-à-vis de la fonction du pharmacien.

${ }^{1}$ Department of Pharmacology and Toxicology, Faculty of Pharmacy; ${ }^{2}$ Department of Medical Chemistry, Faculty of Pharmacy; ${ }^{3}$ Faculty of Medicine; ${ }^{4}$ Research and Development Section, Drug and Food Vice Chancellors' Office, Tabriz University of Medical Sciences, Tabriz, Islamic Republic of Iran (Correspondence to A. Garjani: garjania@tbzmed.ac.ir).

Received: 19/10/06; accepted: 11/01/07 


\section{Introduction}

Rational use of drugs, which has become an important concern of the World Health Organization (WHO) and many countries in recent years, is critical for effective treatment $[1,2]$. Dispensing is one of the main steps in pharmacotherapy and has an important influence on the rationality of drug use. The process necessitates the correct understanding of the instructions of the prescriber and the precise preparation and labelling of the medicine to increase patients' adherence with treatment. These elements are so crucial that any negligence could lead to treatment failure or put the care and health of the patient at risk [3,4]. Appropriate and adequate knowledge of prescribed medicines is essential for patient adherence. The quality of labelling, the time spent informing the patient and the communication skills of the dispenser all contribute to the patient compliance rate and therefore patient outcomes $[5,6]$. Furthermore, prescribing and dispensing errors are often discovered by pharmacists during the consultation with patients [7].

Patient satisfaction is also a key aspect of health care, and it has been shown that there is a strong relationship between communication and patient satisfaction [8]. It is suggested that the attitude of the pharmacist and specialized activities such as providing information and explanations and the convenience of opening hours are not only judged to be important by patients but also influence their satisfaction $[9,10]$. The ultimate goal of patient satisfaction is to improve patient care. Satisfied patients are more likely to adhere to their regimens and exhibit greater continuity with regard to appointments.

Pharmacists are responsible for continuously evaluating the success of the care they provide to ensure quality processes and outcomes. Interaction with the pharmacist can change patients' expectations and satisfaction in areas directly related to pharmaceutical care [11]. Pharmacy nowadays is moving toward a more interventionoriented practice. Pharmacists who work as a team with the patient providers can assist in maximizing clinical benefits and decreasing negative outcomes [12].

In the Islamic Republic of Iran the general presumption is that a pharmacist is only a medicine provider, with no real impact on patient outcomes. On the other hand, polypharmacy, inappropriate use of medications, short consultation times and poor patient compliance are common patterns of irrational use of drugs in this country $[13,14]$. Previous Iranian studies have tended to focus on the prescribing pattern of medicines and have rarely evaluated the pharmacy itself or the work of the pharmacist. To answer the question whether patient satisfaction and information about drugs, as key indicators of patient outcomes, are enhanced by effective pharmacist-patient interaction, we aimed to assess the quality of Tabriz pharmacy services by measuring aspects of pharmacist interaction and to assess patient knowledge of the dispensed drugs and satisfaction with the interaction.

\section{Methods}

\section{Study design}

A prospective study was conducted with a sample of 700 outpatients who received pharmaceutical care from 35 out of 181 community pharmacies in Tabriz from December to March 2005 (20 patients from each pharmacy). The pharmacies and patients were selected randomly. Patients were informed about the study objectives and procedures and that the data collected would be used only for the stated research

المجلة الصحية لشرق المتوسط، منظمة الصحة العالمية، المجلد الخنامس عشر، العدد ع، 9 +. 
purpose. A prestudy assessment was made of the study procedures and data collection forms in 10 community pharmacies, using 50 outpatients. After making changes in the procedures and questionnaires based on the comments of the survey team, a pilot study was carried out in a pilot pharmacy using 90 questionnaires from 90 outpatients.

\section{Structured observation}

A structured observation was carried out by a trained and experienced observer, who observed each pharmacist-patient interaction and the pharmacy activities. To minimize observer bias, the observer was instructed not to interfere with the consultations or dispensing process. The pharmacy staff were not informed about the nature of the survey. The observer recorded the time that the patient spent at the dispensing counter (total dispensing time) and the time during which the patient was being informed about the dispensed medicines (consultation time).

To measure pharmacist-patient interaction we created 5 dichotomous-type questions about specific pharmacist tasks. The questions enquired whether the pharmacist: asked about the patient's history and communicated with the patient verbally; provided written directions for use on the drug package; provided verbal instructions for use, if possible in laymen's terms; ensured the patient's understanding of the instructions; and answered the patient's questions about the medications in a considerate way. Questions were scored as task performed (score 1) or task not performed (score 0 ). To calculate the performance level of each community pharmacy in a specific task the scores were averaged for the 20 patients (maximum score per task). The total pharmacist interaction score for each pharmacy was calculated by summing the task mean scores (maximum score 5 per pharmacy).

\section{Patient knowledge}

Using an interview questionnaire, the same patient's knowledge of dispensed drugs was registered by a second survey team pharmacist, who assessed the patient's recall of: the name of dispensed drugs; the dosage; the duration of treatment; the side-effects; and the reason for the medications. Each attribute was scored as correct (score 1) or incorrect (score 0 ). For each attribute patient's knowledge scores were averaged (maximum score 1 per attribute).

To calculate the overall patient knowledge score, the mean scores of attributes for each pharmacy were summed. Therefore, a total patient knowledge score of 5 indicated patient's correct information about all the questions asked. Misspelling of the names of drugs was disregarded and general explanations about the reasons for medication were considered correct. To assess the influence of pharmacy facilities on patients' satisfaction and knowledge, waiting place area and height of dispensing counter of pharmacies were also measured.

\section{Patient satisfaction}

Five questions enquiring about the overall and differential satisfaction of patients with different aspects of pharmacy services were located at the end of the interviewing questionnaire. The questions asked about the patient's satisfaction with: the waiting time for prescription filling; the pharmacist's explanation and consultation; the availability of the drugs; the prescription costs; and the overall excellence of the services provided. The satisfaction with each item was scored as excellent (score 2), good (score 1) or poor (score 0 ); range $0-2$ points. Scores for questions were summed to produce an overall patient satisfaction score (maximum score 10). 


\section{Data analysis}

All data were expressed as mean and standard deviation (SD) or mean score and 95\% confidence interval (CI). Mean values were compared using the Student $t$-test, as appropriate. Patient knowledge and satisfaction (dependent variables) were correlated against the total pharmacist interaction score and its attributes, dispensing and consultation time, and pharmacy facilities using the Pearson correlation analysis. Stepwise multiple linear regression analysis was employed to discover the most significant factors contributing to pharmacist interaction, patient knowledge and patient satisfaction scores. The factors were selected from among total pharmacist interaction time and its attributes, pharmacy facilities, and dispensing and consultation times. The level of significance in all analyses was set at 0.05 . Statistical calculations were performed with either SPSS, version 11.5, or Instat, version 2, software packages.

\section{Results}

To evaluate the physical and functional status of Tabriz pharmacies, we collected 35 observation questionnaires from 35 randomly selected pharmacies. All the pharmacies had at least 1 and a maximum of 5 staff members as dispensers. According to the Iranian Drug Action Law, the pharmacy services should be delivered only in the presence of a pharmacist who has a PharmD degree and is responsible for dispensing the prescribed drugs as well as counselling the customers. At the time of the study, the pharmacist delivered the drug to the patient in $66 \%$ of cases and in the rest a pharmacy technician acted as dispenser.

In this study, the overall waiting time for prescription filling was 7.6 (SD 3.0) min, but only 1.4 (SD 1.3) min of that was spent on the pharmacist-patient interac- tion, which included verbal communication between the pharmacist and patient and providing written directions for use on the drug package. The mean surface area of the waiting place was 14.4 (SD 7.5) $\mathrm{m}^{2}$ and the mean height of the dispensing counter was 1.16 (SD 0.12) $\mathrm{m}$.

Table 1 shows the mean scores for pharmacist-patient interaction, patient knowledge of dispensed drugs and patient satisfaction with the interaction. The pharmacist interaction received a total mean score of 3.05 out of 5 (range 2.80 to 3.30). The highest contribution to the total interaction score was from the provision of written directions for use on the $\operatorname{drug}(\mathrm{s})$ package (mean score 0.98 out of 1 ). Providing verbal instruction for use to patients, ensuring the patient's understanding of the directions and answering the patient's questions obtained mean scores of $0.68,0.25$ and 0.92 out of 1 respectively. Asking about the patient's history and giving a short introduction attained the lowest mean score, 0.19 .

The total mean score for patient knowledge of dispensed drugs was 3.18 out of 5 . Recalling the name of the $\operatorname{drug}(\mathrm{s})$ (mean score 0.93 out of 1 ) and duration of treatment (mean score 0.85 out of 1 ) were the highest contributing factors to the total score. Recall by the patient of the reason for the medication and the correct dosage received lower mean scores of 0.72 and 0.65 respectively. Patient knowledge of the possible side-effects was very poor (mean score 0.01 out of 1 ).

The total score for patient knowledge of dispensed drugs varied significantly depending on whether the prescription was dispensed by the pharmacist or by a pharmacy staff member $(P<0.002)$. The total mean score for patient knowledge was higher [mean score 3.32 (SD 0.35)] for patients who received their medication from the pharmacist in comparison with those

المجلة الصحية لشرق المتوسط، منظمة الصحة العالمية، المجلد الخامس عشر، العدد ع، 9 +. 


\begin{tabular}{|c|c|}
\hline Dimension/evaluation item & Mean score $(95 \% \mathrm{Cl})$ \\
\hline \multicolumn{2}{|l|}{ Pharmacist interaction score } \\
\hline Total $^{\mathrm{a}}$ & 3.05 (2.80 to 3.30$)$ \\
\hline Obtaining patient's history ${ }^{b}$ & $0.19(0.12$ to 0.26$)$ \\
\hline Providing written directions for use ${ }^{b}$ & 0.98 (0.95 to 1.02$)$ \\
\hline Providing verbal instructions for use $\mathrm{b}^{\mathrm{b}}$ & $0.68(0.55$ to 0.81$)$ \\
\hline Ensuring patient's understanding of instructions ${ }^{b}$ & 0.25 (0.16 to 0.33$)$ \\
\hline Answering patient's questions about medications ${ }^{b}$ & $0.92(0.85$ to 0.99$)$ \\
\hline \multicolumn{2}{|l|}{ Patient knowledge score } \\
\hline Total $^{a}$ & 3.18 (3.04 to 3.32$)$ \\
\hline Recalling name of dispensed drugs ${ }^{b}$ & 0.93 (0.91 to 0.96$)$ \\
\hline Recalling correct dosage of dispensed drugs ${ }^{b}$ & 0.65 (0.58 to 0.72$)$ \\
\hline Recalling duration of the treatment ${ }^{\mathrm{b}}$ & 0.85 (0.81 to 0.89$)$ \\
\hline Recalling side-effects of dispensed drugs ${ }^{b}$ & 0.01 (0.00 to 0.02$)$ \\
\hline Recalling reason for medications ${ }^{b}$ & $0.72(0.66$ to 0.78$)$ \\
\hline \multicolumn{2}{|l|}{ Patient satisfaction score } \\
\hline Total $^{c}$ & $5.20(4.90$ to 5.50$)$ \\
\hline
\end{tabular}

$\mathrm{Cl}=$ confidence interval.

who obtained it from a pharmacy technician [mean score 2.85 (SD 0.29)]. The estimate for the difference was $0.45(95 \%$ CI $0.18-$ 0.72 ). However, patient satisfaction was not significantly different comparing those receiving services from a pharmacist [mean score 5.36 (SD 0.86)] and those receiving services from a pharmacy technician [mean score $4.90(\operatorname{SD~0.66)]}(P=0.120)$.

The effect of the performance level of pharmacies on patient knowledge of dispensed drugs and patient satisfaction was investigated using correlation analysis. The analysis was performed between patient knowledge or patient satisfaction scores as the dependent variable and total pharmacist interaction score or its contributing elements (pharmacists' tasks), total dispensing time, consultation time, surface area of waiting place and height of dispensing counter as independent variables. There was a strong positive relation between the total pharmacist interaction score and patient knowledge $(r=0.93 ; P=0.0001)$ (Table 2). The degree of satisfaction was also significantly associated with the total pharmacist interaction score $(r=0.44 ; P=0.008)$. Close positive correlations were observed between patient knowledge of dispensed drugs and some of the specific pharmacist tasks, including mean scores for obtaining patient's history, provision of verbal directions (explanation of labelling) and ensuring patient understanding. Only mean score for provision of verbal directions, however, was associated significantly with the patient satisfaction score $(r=0.57 ; P=0.0003)$. There was no correlation between patient knowledge or satisfaction scores with the area of the pharmacy waiting room or the height of the dispensing counter $(P>0.35)$. Although patient knowledge of dispensed drugs was not related to the total dispensing time, it was markedly associated with counselling time $(r=0.64 ; P=0.0001)$. A significant inverse relationship $(r=-0.56 ; P=0.0005)$ 


\begin{tabular}{|c|c|c|c|c|}
\hline \multirow[t]{2}{*}{ Variable } & \multicolumn{2}{|l|}{ Knowledge } & \multicolumn{2}{|l|}{ Satisfaction } \\
\hline & $r(95 \% \mathrm{Cl})$ & $P$-value ${ }^{a}$ & $r(95 \% \mathrm{Cl})$ & $P$-value \\
\hline \multicolumn{5}{|l|}{ Pharmacist interaction score } \\
\hline Total pharmacist interaction score & $0.93(0.86$ to 0.96$)$ & 0.0001 & 0.44 (0.12 to 0.67$)$ & 0.008 \\
\hline Obtaining patient's history & 0.79 (0.62 to 0.89$)$ & 0.0001 & $0.26(-0.08$ to 0.55$)$ & 0.132 \\
\hline Providing written directions for use & $0.33(-0.01$ to 0.60$)$ & 0.054 & $-0.07(-0.39$ to 0.27$)$ & 0.689 \\
\hline Providing verbal instruction for use & $0.80(0.64$ to 0.89$)$ & 0.0001 & $0.57(0.29$ to 0.76$)$ & 0.0003 \\
\hline $\begin{array}{l}\text { Ensuring patient's understanding } \\
\text { of instructions } \\
\text { Answering patient's questions }\end{array}$ & $0.84(0.70$ to 0.92$)$ & 0.0001 & $0.32(-0.01$ to 0.59$)$ & 0.055 \\
\hline about medications & 0.35 (0.01 to 0.61$)$ & 0.041 & $0.11(-0.24$ to 0.42$)$ & 0.545 \\
\hline \multicolumn{5}{|l|}{ Interaction time } \\
\hline Total dispensing time & $-0.01(-0.34$ to 0.32$)$ & 0.943 & $-0.56(-0.75$ to -0.28$)$ & 0.0005 \\
\hline Consultation time & $0.64(0.34$ to 0.80$)$ & 0.0001 & $0.38(0.05$ to 0.63$)$ & 0.025 \\
\hline \multicolumn{5}{|l|}{ Pharmacy facilities } \\
\hline Floor space of waiting area & $-0.15(-0.46$ to 0.19$)$ & 0.384 & $-0.06(-0.39$ to 0.27$)$ & 0.720 \\
\hline Height of dispensing counter & $-0.10(-0.42$ to 0.24$)$ & 0.578 & $-0.08(-0.40$ to 0.26$)$ & 0.658 \\
\hline
\end{tabular}

was observed between total dispensing time and patient satisfaction score. Consultation time, however, had a positive and significant influence on patient satisfaction $(P<0.05)$.

In order to identify the factors which were most influential on patient satisfaction and knowledge, stepwise regression analyses were performed between patient satisfaction or knowledge scores as the dependent variable and the possible underlying factors of total interaction score and its attributes, total dispensing time, consultation time, surface area of waiting room and height of dispensing counter as the independent variables (Tables 3 and 4). A significant and marked correlation was observed between pharmacist-patient interaction (beta $=0.82 ; P=0.0001$ ) as well as pharmacist consultation time (beta $=0.21 ; P=0.005)$ and patient knowledge score. Likewise, pharmacist consultation time and waiting room area had positive and significant influences on patient satisfaction
$(P=0.0001 ; P=0.01)$. Again, a significant inverse relationship was identified between total dispensing time and satisfaction score (beta $=-0.77 ; P=0.0001$ ).

Total interaction score, as the underlying factor in patient knowledge, was further analysed through stepwise regression in order to identify the specific tasks with higher promoting effects as the predictors. The most effective tasks in promoting the pharmacist-patient interaction score were provision of verbal instructions (beta $=0.39 ; P=0.0001)$ and obtaining patient's history (beta $=0.32 ; P=0.0001$ ) (Table 5). Provision of written directions was the least effective parameter $($ beta $=0.09 ; P$ $=0.013$ ).

\section{Discussion}

In this study the mean scores of 3.05 and 3.18 for pharmacist-patient interaction and 


\begin{tabular}{lccccr}
\hline Table 3 Stepwise regression analysis of patient knowledge of dispensed drugs & \\
\hline Variable & \multicolumn{2}{c}{$\begin{array}{c}\text { Unstandardized } \\
\text { coefficient }\end{array}$} & $\begin{array}{c}\text { Standardized } \\
\text { coefficient } \\
\text { Beta }\end{array}$ & -value & $P$-value \\
& B & SE & Beta & \\
\hline (Constant) & 1.790 & 0.099 & - & 18.080 & $<0.001$ \\
Total pharmacist interaction score & 0.426 & 0.035 & 0.82 & 12.006 & $<0.001$ \\
Consultation time & 0.067 & 0.022 & 0.21 & 3.055 & 0.005 \\
\hline
\end{tabular}

Total patient knowledge of dispensed drugs analysed against total pharmacist interaction score, total dispensing time, dispensing consultation time, floor space of waiting area and height of dispensing counter. Correlation coefficient of multiple regression equation was 0.945 ; only parameters with $P<0.05$ were accepted. SE $=$ standard error.

patient knowledge represent $61 \%$ and $63 \%$ of the total scores respectively. Patient knowledge of the dispensed drugs is one of the essential prerequisites for patient compliance with treatment. On the other hand, the quality of the consultation and information provided by pharmacy staff is the important determinant of patient knowledge $[15,16]$. A strong and positive relationship between the pharmacist-patient interaction and patient knowledge and satisfaction in this study confirms the essential role of the pharmacist in promoting patient adherence to medications.

The mean dispensing consultation time in Tabriz was 1.35 (SD 1.3) min. In comparison with the total prescription filling time [7.6 (SD 3.0) $\mathrm{min}$ ] the consultation time was short, but compared to some other studies the time was relatively good. In a Nigerian study the mean dispensing counselling time was $13 \mathrm{~s}$ [17] and in a study from Botswana it was $25 \mathrm{~s}$ [4]. The counselling time during dispensing, which includes verbal communication between the pharmacist and the patient, is an effective indicator of better patient knowledge and satisfaction.

Among the pharmacist tasks, the communicative tasks such as "obtaining patient's history", "providing verbal instructions for use", and "ensuring patient's understanding of instructions" had the most positive relationship with patient knowledge. Although "providing written directions for use" on the drug package attained a high mean score of 0.98 out of 1 , it had no significant effect on patient knowledge. This indicates that written directions are useful only when they are accompanied by an explanation. The person dispensing the drugs is in a position to reinforce the information about the medications.

In this study we found that, compared to the general dispensing staff, pharmacists imparted a more satisfactory level of knowledge to patients. This shows that the level of qualification and education of dispensers is one of the main determents of patient knowledge of dispensed drugs. However, patient satisfaction did not differ between patients who received service from a pharmacist or those who received service from a staff member. Patient expectations and attitudes play important roles in their evaluation of a service; therefore we believe that real satisfaction occurs when it matches knowledge. It has been shown that communication with the pharmacist at community pharmacies or communication with the physician during the examination is strongly related to patient satisfaction $[9,18]$.

In addition to consultation time, provision of verbal directions by pharmacists considerably influenced patient satisfaction, while total waiting time at the counter had the reverse effect on satisfaction. 


\begin{tabular}{|c|c|c|c|c|c|}
\hline \multirow[t]{2}{*}{ Variable } & \multicolumn{2}{|c|}{$\begin{array}{l}\text { Unstandardized } \\
\text { coefficient }\end{array}$} & \multirow{2}{*}{$\begin{array}{c}\text { Standardized } \\
\text { coefficient } \\
\text { Beta }\end{array}$} & \multirow[t]{2}{*}{$t$-value } & \multirow[t]{2}{*}{$P$-value } \\
\hline & B & SE & & & \\
\hline$\overline{\text { (Constant) }}$ & 5.789 & 0.284 & - & 20.351 & $<0.001$ \\
\hline Total dispensing time & -0.215 & 0.033 & -0.77 & -6.476 & $<0.001$ \\
\hline Consultation time & 0.383 & 0.074 & 0.61 & 5.154 & $<0.001$ \\
\hline Floor space of waiting area & 0.036 & 0.013 & 0.34 & 2.771 & 0.009 \\
\hline
\end{tabular}

Total pharmacist interaction score was the most important parameter in increasing patient knowledge, and consultation time was the second most important factor that leads to greater patient knowledge. Although more robust investigation is required to assess the outcome of pharmacy-based intervention on the knowledge and attitudes of patients, this preliminary finding could have interesting implications with regard to the feasibility of effective education for patients through community pharmacies. This is because, with the majority of patients receiving written directions for use, the variation in this task has become limited.

Although obtaining the patient's history and provision of verbal instruction were the most effective factors in increasing the total pharmacist interaction score, it cannot be concluded that they are the prominent factors affecting patient knowledge. Therefore, patient knowledge was directly correlated against specific pharmacist tasks using stepwise regression. The standardized coefficients value of various tasks showed that ensuring patient understanding and provision of verbal drug information were the most effective tasks in promoting patient knowledge. In the interpretation of this result it should be borne in mind that, clearly, ensuring patient understanding is not possible without first providing verbal drug information. Therefore it is only logical to assume that, although ensuring patient understanding is a more significant parameter than provision of verbal drug information according to the statistical analysis, it cannot be concluded that the latter is a less effective factor in promoting patient knowledge.

Patient satisfaction, the other key factor investigated in this study, was influenced by total dispensing time, consultation time and waiting room area in descending importance according to the standardized coefficients. Total dispensing time inversely affected patient satisfaction, whereas patients appreciated consultation time and the waiting room area. Increasing significance level to $P$ $<0.10$, a fourth parameter (providing verbal instructions to patients) will be permitted in the multiple regression analysis with a positive effect on patient satisfaction.

\section{Conclusions}

This study showed that the interaction and consultation of pharmacists with patients increases patient knowledge of dispensed medicines and satisfaction. Communicative tasks had the most positive relationship on patient knowledge and satisfaction. However, writing directions for use on the drug package, which is the routine practice of pharmacists, had no significant effect on

المجلة الصحية لشرق المتوسط، منظمة الصحة العالمية، المجلد الخامس عشر، العدد ع، 9 +. 


\begin{tabular}{|c|c|c|c|c|c|}
\hline \multirow[t]{2}{*}{ Evaluation item/variable } & \multicolumn{2}{|c|}{$\begin{array}{l}\text { Unstandardized } \\
\text { coefficient }\end{array}$} & \multirow{2}{*}{$\begin{array}{c}\text { Standardized } \\
\text { coefficient } \\
\text { Beta }\end{array}$} & \multirow[t]{2}{*}{$t$-value } & \multirow[t]{2}{*}{$P$-value } \\
\hline & B & SE & & & \\
\hline \multicolumn{6}{|l|}{ Pharmacist interaction score } \\
\hline (Constant) & -0.072 & 0.423 & - & -0.170 & 0.866 \\
\hline Obtaining patient's history & 1.284 & 0.180 & 0.32 & 7.127 & $<0.001$ \\
\hline Providing verbal instructions for use & 0.831 & 0.092 & 0.39 & 9.001 & $<0.001$ \\
\hline $\begin{array}{l}\text { Answering patient's questions about } \\
\text { medications }\end{array}$ & 1.012 & 0.140 & 0.26 & 7.225 & $<0.001$ \\
\hline $\begin{array}{l}\text { Ensuring patient's understanding of } \\
\text { instructions }\end{array}$ & 0.912 & 0.138 & 0.29 & 6.593 & $<0.001$ \\
\hline Providing written instructions for use & 1.172 & 0.443 & 0.09 & 2.646 & 0.013 \\
\hline \multicolumn{6}{|l|}{ Patient knowledge score } \\
\hline Constant & 2.385 & 0.100 & - & 23.885 & $<0.001$ \\
\hline $\begin{array}{l}\text { Ensuring patient's understanding of } \\
\text { instructions }\end{array}$ & 0.747 & 0.108 & 0.46 & 6.937 & $<0.001$ \\
\hline Providing verbal instructions for use & 0.382 & 0.071 & 0.34 & 5.359 & $<0.001$ \\
\hline Obtaining patient's history & 0.601 & 0.139 & 0.29 & 4.320 & $<0.001$ \\
\hline Answering patient's questions about & 0.252 & 0.109 & 0.12 & 2.305 & 0.028 \\
\hline
\end{tabular}

Correlation coefficients of multiple regression equations were 0.985 for total pharmacist interaction score and 0.964 for total patient knowledge score; only parameters with significance level $P<0.05$ were accepted.

SE $=$ standard error.

patient knowledge, indicating that written directions are useful only when they are accompanied by an explanation. The most effective tasks in promoting the pharmacistpatient interaction score were provision of verbal instruction and obtaining patients' history. We also showed that, compared to dispensing by pharmacy technicians, dispensing by pharmacists resulted in a higher level of knowledge in patients.

\section{Acknowledgements}

This study was supported by the Research Vice-Chancellors of Tabriz University of Medical Sciences. The authors thank to all pharmacists involved in the study for their cooperation and hospitality, faculty members of Tabriz Faculty of Pharmacy and colleagues at the Directorate General of Drugs and Food.

\section{References}

1. Kohn L, Corrigan J, Donaldson M. To err is human: building a safer health system. Washington, DC, Institute of Medicine, National Academy Press, 1999.

2. Quick JD, Management Sciences for Health and World Health Organization. Managing drug supply: the selection, procurement, distribution, and use of pharmaceuticals, 2nd ed. West Hartford Kumarian Press, 1997.

3. Hogerzeil HV et al. Field tests for rational drug use in twelve developing countries. Lancet, 1993, 342:1408-10.

4. Boonstra $E$ et al. Labelling and patient knowledge of dispensed drugs as quality 
indicators in primary care in Botswana. Quality and safety in health care, 2003, 12:168-75.

5. Hogerzeil HV. Promoting rational prescribing: an international perspective. British journal of clinical pharmacology, 1995, 39:1-6.

6. Injection practices in the developing word. Geneva, World Health Organization, 1996 (WHO/DAP/96.4).

7. Davis NM, Cohen MR. Counseling reduces dispensing accidents. American pharmacy, 1992, NS32 (10):22.

8. Giltlow HS, Melby M. Framework for continuous quality improvement in the provision of pharmaceutical care. American journal of hospital pharmacy, 1991 48:1917-25.

9. Kamei $\mathrm{M}$ et al. Investigation of patients' demand for community pharmacies: relationship between pharmacy services and patient satisfaction. Yakugaku zasshi, 2001, 121(3):215-20.

10. Hayashi S-I. et al. Classification of pharmaceutical services from the viewpoint of patient satisfaction/dissatisfaction. Yakugaku zasshi, 2005, 125(1):159-68.

11. Volume $\mathrm{Cl}$ et al. Pharmaceutical care research and education project: patient outcomes. Journal of the American Pharmaceutical Association, 2001, 41:41120.
12. Okamoto MP, Nakahiro RK. Pharmacoeconomic evaluation of a pharmacist-managed hypertension clinic. Pharmacotherapy, 2001, 21:1337-44.

13. Gholamreza-Sepehri, Meimandi MS. The quality of prescribing in general practice in Kerman, Iran. International journal of health care quality assurance incorporating Leadership in health services, 2005, 18(4-5):353-60.

14. Cheraghali AM et al. Evaluation of availability, accessibility and prescribing pattern of medicines in the Islamic Republic of Iran. Eastern Mediterranean health journal, 2004, 10(3):406-15.

15. Kruse $\mathrm{G}$ et al. Rationality of drug prescriptions in rural health centers in Burkina Faso. Health policy and planning, 1999, 14:291-8.

16. Wilson $\mathrm{M}$ et al. Customers' recall of information given in community pharmacies. International journal of pharmacy practice, 1992, 1:152-9.

17. How to investigate drug use in health facilities: selected drug use indicators. Geneva, World Health Organization, 1993 (WHO/DAP/93.1).

18. Hagihara A et al. A signal detection approach to patient-doctor communication and doctor-shopping behaviour among Japanese patients. Journal of evaluation in clinical practice, 2005, 11(6):556-67. 